\title{
Association Between Neutrophilic Leucocytosis And Congestive Heart Failure After Acute Myocardial Infarction
}

\author{
Khatri $D^{1}$, Islam $\mathbf{N}^{2}$, Ali A $^{3}$ \\ ${ }^{1}$ Dr. Devendra Khatri, Consultant cardiologist, Birendra Hospital, Chhauni. 2P rof. Nazrul Islam, Director, National \\ Institute of Cardiovascular Diseases, Dhaka. ${ }^{3}$ Associate Prof. National Institute of Cardiovascular Diseases, Dhaka.
}

\begin{abstract}
Introduction: Acute myocardial infarction is associated with inflammation which is marked by peripheral leucocytosis and relative neutrophilia. The elevation of white blood cell count (WBC) count usually develops within 2 hours after the onset of chest pain, reaches a peak 2-4 days after infarction, and returns to normal within 7 days. The objective of this study was to find out the association between peripheral leucocyte count and the neutrophil percentage and the development of congestive heart failure in the patients with acute myocardial infarction (AMI).

Methods and result: The Prospective observational study was carried out over the period of 2 yrs where a total of one hundred and fifty acute myocardial infarction (AMI) patients, with less than 12 hrs of chest discomfort, irrespective of age and sex were studied. Outcome measures included clinical episodes of congestive heart failure (CHF) with confirmatory chest X-ray findings and/ or echocardiographic evidence of contractile dysfunction. $54 \%$ patients had leucocytosis and $60.7 \%$ of patients had relative neutrophilia. Amongst heart failure patients $82.3 \%$ had leucocyte $>11.0 \times 10^{9} / \mathrm{l}$ and only $17.7 \%$ cases had count $\leq 11.0 \times 10^{9} / \mathrm{l}$, whereas among the patients who did not develop heart failure, total leucocyte count $>$ $11.0 \times 10^{\circ} / \mathrm{l}$ was in $35.2 \%$ cases and in $64.8 \%$ cases it was $\leq 11.0 \times 10^{9} /$. The sensitivity of leucocytosis for the prediction of $\mathrm{CHF}$ was $82.3 \%$ with specificity of $64.8 \%$. Amongst the patients with heart failure $93.5 \%$ had neutrophil count $>65 \%$ and only $6.5 \%$ of cases had count $\leq 65 \%$.

Conclusion: The study demonstrated a significant association between neutrophilic leucocytosis and even relative neutrophilia on admission to the hospital and the subsequent development of congestive heart failure in patients with ST elevation myocardial infarction with good sensitivity, specificity. This association helps in the identification of high risk individuals who might benefit from more aggressive interventions to prevent or reduce the risk of congestive heart failure.
\end{abstract}

Key words: leucocytosis, neutrophilia, myocardial infarction, congestive heart failure.

\section{Introduction}

Despite impressive improvement in diagnosis and management over the past decades, acute myocardial infarction is the major public health problem in the industrialized world and is becoming an increasingly important problem in developing countries. Of particular concern from a global perspective are projections from the World Heart Federation that the burden of disease in developing countries will become more closely aligned with that now afflicting developed countries because of accelerated economic development and life style changes promoting atherosclerosis.

Almost all myocardial infarctions result from coronary atherosclerosis with superimposed coronary thrombosis. It has commonly been shown to occur as a result of the disruption of atherosclerotic plaque at a site of a high density of inflammatory cells and acute thrombotic occlusion of a coronary artery with resulting downstream necrosis ${ }^{1}$. Atherosclerosis is not a single disease entity; rather it represents a common response of the artery to numerous potentially different forms of insult. Atherosclerosis is a complex inflammatory fibroproliferative response to retention of plasma derived

Address for correspondence: drdbkhatri@yahoo.com. atherogenic lipoproteins in the arterial intima. ${ }^{2}$ Thus inflammation plays an important role in the initiation and progression of atherosclerosis and systemic blood markers of inflammation including leucocyte count have emerged as a powerful predictor of coronary events. ${ }^{3}$

Acute myocardial infarction (AMI) is frequently associated with leucocytosis and an elevated peripheral neutrophil count. The elevation of white blood cell count (WBC) count usually develops within 2 hours after the onset of chest pain, reaches a peak 2-4 days after infarction, and returns to normal within 7 days; the peak white cell count usually ranges between 12,000 to $15,000 / \mathrm{cmm}$ but occasionally rises to as high as $20,000 / \mathrm{cmm}$ in patients with large transmural acute myocardial infarction. Often there is an increase in the percentage of polymorphonuclear leucocytes and a shift of the differential count to the band forms ${ }^{4}$.

Acute myocardial infarction is the leading cause of mortality \& morbidity all over the world. Congestive heart failure $(\mathrm{CHF})$ is one of the most common complications occurring after acute myocardial infarction. Rates of post infarction congestive heart failure ranging from $51 \%$ to $71 \%$ have been reported in elderly populations. ${ }^{5}$ Congestive heart failure is associated with 5 year mortality of about $50 \%$ and 
the health care cost is reasonably high. Although the cause of contractile dysfunction in congestive heart failure may be multi-factorial, accumulating evidence suggests that oxidative stress and the release of proinflammatory mediators during myocardial ischaemia probably contributes to its development. ${ }^{6}$

\section{Methods}

The $\mathrm{P}$ rospective observational study was carried out over the period of 2 yrs where a total of one hundred and fifty acute myocardial infarction (AMI) patients, with less than 12 hrs of chest discomfort, irrespective of age and sex were included. Patients with more than $12 \mathrm{hrs}$ of onset of symptoms before hospital admission, acute myocardial infarction presenting with congestive heart failure requiring immediate treatment - Killip class II-IV, prior myocardial infarction, uncontrolled severe hypertension ( $B P \geq 180 / 110 \mathrm{~mm} \mathrm{Hg}$ ). uncontrolled Diabetes Mellitus (RBS $\geq 15 \mathrm{~m} \mathrm{~mol} /$ ), evidence of acute or chronic infection, serious systemic disorders like chronic renal failure, patients using corticosteroids, patients suffering from malignant disorders and inflammatory disorders such as rheumatoid arthritis, gout, rheumatic fever etc. were not included in the study.

On admission ECG for the location of myocardial infarct and capillary blood from finger prick for total and differential count of White Blood Cell was obtained. Patients were classified into different groups according to total WBC count and neutrophil percentage. Total leucocytes count more than $11 \times 10^{9} / \mid$ and neutrophil count $>65 \%$ were considered as leucocytosis and neutrophilia respectively. All the patients selected for the study were followed up during hospital stay. C linical evaluation for the presence of heart failure was done during follow-up. Features of congestive heart failure (CHF) were documented and echocardiographic evaluation was done for all the selected patients. Documented clinical symptoms and signs of heart failure according to the Killip classification and evidence of left ventricular dysfunction i.e. ejection fraction (EF) $<40 \%$ in echocardiography was taken into account.

Subsequent statistical analysis was done with emphasis particularly on neutrophilic leucocytosis, location of infarctand presence or absence of congestive heart failure. Compiled data were analyzed by using computer based package for Social science (SPSS) version 11.0 for windows. Mean \pm standard deviation was calculated for continuous variables and absolute and relative frequencies were measured for discrete variables. The statistical significance of differences between groups was analyzed by chi-square test in discrete variables. Student's t-test was used to analyze the continuous variables. The $p$ values less than 0.05 were considered as significant.

\section{Observation and Results}

Total 150 patients of acute myocardial infarction were studied out of which 137 were male and 13 were female. The mean age of the patients was a $53.4 \pm 9.2$ year ranging from 36 to 75 years. The highest percentage of patients $(35.8 \%)$ was in the age range of $50-59$ years. The mean age of the heart failure patients was $56.4 \pm 9.6$ years and the patient without heart failure was $51.2 \pm 8.2$ years. The mean difference was statistically significant $(p<0.05)$ indicating the heart failure patients had higher age compared to without heart failure patients. In the study carried out by E manuelsson et al ${ }^{5}$, they observed congestive heart failure in $51 \%$ of cases of myocardial infarction and patients with congestive heart failure were older. No statistically significant difference was found between male and female patients in regards to heart failure $(p>0.05)$.

Among the important risk factors of coronary artery disease $46.7 \%$ were hypertensive, $46 \%$ were smoker, $20 \%$ were diabetics and $13.3 \%$ were dyslipidaemic and only $2.0 \%$ had family history of ischaemic heart disease. The mean number risk factor was $1.3 \pm 0.8$ years ranging from 0 to 3 . Among the male patients, the average number of risk factors was $1.3 \pm 0.8$ and that of female patients was $1.2 \pm 0.9$. There was no significant statistical difference in terms of risk factor and development of heart failure $(p>0.05)$, although hypertension, smoking, diabetes and dyslipidaemia were higher amongst the patients who developed heart failure.

Present study showed that $41.3 \%$ patients developed heart failure during treatment and $58.7 \%$ did not. The mean day of onset of heart failure was

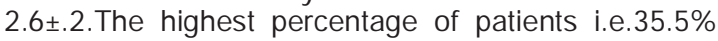
developed heart failure on 2 nd day followed by $22.6 \%$ and $19.4 \%$ on 3 rd day and 1st day respectively. Amongst the heart failure patients $35.4 \%$ had ejection fraction less than $40 \%$. Cardiac enzyme (CK-MB) was higher among the patients with heart failure as compared to those without heart failure. Among the heart failure patients, it was $81.7230 .03 \mathrm{IU} / \mathrm{l}$ and the patients having no heart failure was $64.96 \pm 16.34$. This finding is very much consistent with the finding of the study carried out by $\mathrm{Kyne} \mathrm{et} \mathrm{al}^{7}$ who reported heart failure in $43 \%$ of the post MI patients.

The mean number blood leucocyte count was $13.7 \times 10^{9} / /$ among the patients who developed heart failure during the hospital stay and it was $11.3 \times 10^{9} / \mathrm{l}$ in the patients who did not develop heart failure and the mean difference was statistically significant $(p<0.001)$. It was also found that among the patients with heart failure $82.3 \%$ had leucocyte more than $11.0 \times 10^{\%} /$ and only $17.7 \%$ had less than $11.0 \times 10^{9} / I$, whereas among the patients who did not develop heart failure, total leucocyte count more than $11.0 \times 10^{9} / /$ was in $35.2 \%$ cases and in $64.8 \%$ cases it was less than $11.0 \times 10 \%$. The relative risk indicates, the total leucocyte count more than normal was 8.52 times higher among the patients with heart failure than the patients without heart failure. This finding is very much consistent with the reports made by Furman et $\mathrm{al}^{8}$ in the findings from the G lobal Registry of Acute Coronary Events (GRACE) where they reported that increasing leucocyte count is significantly associated with hospital death and heart failure for patients presenting with ACS. They also reported a $7 \%$ increase in odds of developing heart failure. In the study carried out by Menon et al ${ }^{9}$ they found that the patients with upper quintiles of WBC count (count $>11.1 \times 10^{9} /$ ) were at increased risk of heart failure.

The mean percentage of neutrophil count was $77.9 \pm 6.2 \%$ among the patients with heart failure and in patients without heart failure it was $68.0 \pm 8.7 \%$. The mean difference was statistically significant $(p<0.001)$. 
It was also found that among the patients with heart failure $93.5 \%$ had neutrophil count more than $65 \%$ and only $6.5 \%$ of cases had count less than or equal to $65 \%$. Whereas amongst the patients without heart failure, percentage of neutrophil count was more than $65 \%$ only in $37.5 \%$ cases and $62.5 \%$ had count less than or equal to $65 \%$. This finding is similar to the finding of Kyne et al. ${ }^{7}$ They reported development of heart failure after AMI in $92.5 \%$ of the cohort in whom neutrophil percentage was $>65 \%$ compared to $45 \%$ of those in whom CHF did not develop. The relative risk indicates that the total neutrophil count was 24.16 times higher among the patients with heart failu re than the patients without heart failure.

Table 1: Baseline characterstics of the study cohort

Total Patients

150 (male-137; female -13)

Age

36-75 ( mean 53.4 \pm 9.2 )

\begin{tabular}{|c|c|c|}
\hline \multicolumn{3}{|l|}{ Risk factors } \\
\hline & Hypertension & $73(46.7 \%)$ \\
\hline & Smoking & $70(46.0 \%)$ \\
\hline & Diabetes Mellitus & $34(20.0 \%)$ \\
\hline & Dyslipidaemia & $24(13.3 \%)$ \\
\hline & F amily history of CAD & $7(2.0 \%)$ \\
\hline \multicolumn{3}{|l|}{ Laboratory test results } \\
\hline & TLC $>11 \times 10^{9}$ & $82(54.7 \%)$ \\
\hline & TLC $<11 \times 10^{9}$ & $68(453 \%)$ \\
\hline & Neutrophil $>65 \%$ & $91(607 \%)$ \\
\hline & Neutrophil $<65 \%$ & $59(39.3 \%)$ \\
\hline & Lymphocyte $\leq 25 \%$ & $97(64.7 \%)$ \\
\hline & Lymphocyte $>25 \%$ & $53(353 \%)$ \\
\hline & CK-MB & $50-264$ IU/I $($ mean $71.89 \pm 24.37)$ \\
\hline \multicolumn{3}{|l|}{ Location of Infarct } \\
\hline & Anterior & $77(51.3 \%)$ \\
\hline & Inferior & $55(36.7 \%)$ \\
\hline & NSTEMI & $18(12.0 \%)$ \\
\hline Mean Hospital stay days & $8.1 \pm 3.4$ & \\
\hline \multicolumn{3}{|l|}{ Outcome } \\
\hline & Recovered & $143(95.3 \%)$ \\
\hline & Death & $7(47 \%)$ \\
\hline
\end{tabular}


Table 2: Distribution of the study patients by heart failure and total leucocyte count

\begin{tabular}{|l|c|c|c|c|}
\hline \multirow{2}{*}{ Leucocyte count } & \multicolumn{2}{|c|}{ Heart Failure } & Total & N(\%) \\
\cline { 2 - 5 } & Present $\mathbf{n}(\%)$ & Absent $\mathbf{n}(\%)$ & $82(54.7)$ & 0.001 \\
\hline$>11.0 \times 10^{9}$ & $51(82.3)$ & $31(35.2)$ & $68(45.3)$ & \\
\hline Total & $11(17.7)$ & $57(64.8)$ & $150(100.0)$ & \\
\hline Mean \pm SD & $62(41.3)$ & $88(58.7)$ & $12.3 \times 10^{9}$ & \\
\hline
\end{tabular}

Figure in parenthesis indicate percentage, $\mathrm{n}$ denotes number of patients.

$\mathrm{p}$ value reached from chi -square test $(p<0.001)$

Sensitivity $=82.3 \%$, Specificity $=64.8 \%$, Predictive accuracy $=72.0 \%$, Relative risk $=8.525(95 \% \mathrm{Cl}=3.889-18.686)$

Table 3: Distribution of the study patients by congestive heart failure and neutrophil count

\begin{tabular}{|c|c|c|c|c|}
\hline \multirow{2}{*}{ Neutrophil count } & \multicolumn{2}{|c|}{ Heart Failure } & Total & P value \\
\cline { 2 - 3 } & Present $\mathbf{n}(\%)$ & Absent $\mathbf{n}(\%)$ & N(\%) & 0.001 \\
\hline$\leq 65 \%$ & $58(93.5)$ & $33(37.5)$ & $91(60.7)$ & \\
\hline Total & $4(6.5)$ & $55(62.5)$ & $59(39.3)$ & \\
\hline Mean \pm SD & $62(41.3)$ & $88(58.7)$ & $150(100.0)$ & \\
\hline
\end{tabular}

Figure in parenthesis indicate percentage, $\mathrm{n}$ denotes number of patients. $p$ value reached from chi- square test $(p<0.001)$

Sensitivity $=93.5 \%$, Specificity $=62.5 \%$, Predictive accuracy $=75.3 \%$, Relative risk $=24.167(95 \% \mathrm{Cl}=8.034-72.695)$

During this study it was also observed that among the patients with heart failure $82.3 \%$ of patients had neutrophilic leucocytosis, followed by neutrophilia without leucocytosis in $11.3 \%$ and only $6.5 \%$ had normal range of leucocyte and neutrophil count. Whereas, in patients without heart failure, highest percentage $(62.5 \%)$ had normal range of leucocyte and neutrophil count followed by neutrophilic leucocytosis in $35.2 \%$ and in $2.3 \%$ neutrophilia only without leucocytosis. The difference was statistically significant $(p<0.001)$ indicating that the patients with heart failure, neutrophilic leucocytosis and isolated neutrophilia was significantly higher among the patients with heart failure compared to those without heart failure. To add to the fact that in those patients who had neutrophilia only, their leucocyte count was at the higher range of normal limit.

Analysis also revealed that amongst the patients who developed congestive heart failure, $58.1 \%$ had anterior myocardial infarction followed by inferior myocardial infarction in $32.3 \%$ and NSTEMI in $9.7 \%$. Similar pattern of myocardial infarction was found among the patients without congestive heart failure with highest percentage of anterior myocardial infarction $(46.6 \%)$ followed by inferior myocardial infarction $(39.8 \%)$ and NSTEMI (13.6\%).The proportion of anterior MI was higher among the patients who were found to have developed CHF and proportions of NSTEMI and inferior MI was higher among the patients without heart failure. However, no statistically significant association was found between heart failure and type of myocardial infarction $(p>0.05)$.
Statistical analysis to find out the relationship of congestive heart failure with leucocytes count and neutrophil count in different type of $\mathrm{MI}$ revealed that in anterior MI and inferior MI with heart failure, the leucocyte count and neutrophil count were significantly higher as compared to those without heart failure. This finding agrees with previous findings of Kyne et $\mathrm{al}^{7}$ who concluded neutrophilia $>65 \%$ and leucocytosis $>11 \times 10^{9} / \mid$ to be the positive predictor of $\mathrm{CHF}$ and Furman et $\mathrm{al}^{8}$ who reported the association seen between increased leucocyte count and heart failure in patients with ST segment elevation AMI. But in case of NSTEMI with heart failure the difference was not statistically significant $(p>0.05)$. This finding is not similar with finding of Furman et al. ${ }^{8}$ who showed positive association between leucocytosis and heart failure in NSTEMI also. This could be due to small number of patients included in this group; still incidence of heart failure was higher with increased leucocyte count and neutrophil count.

In hospital follow-up of the study patients total $7(4.7 \%)$ patients succumbed to death and the proportion of death among the heart failure patients was significantly higher. This finding is supported by the findings of Furman et al. ${ }^{10}$ They reported increased in-hospital case fatality rates mostly due to congestive heart failure and cardiogenic shock with increasing quintiles of leucocyte count. 
Table 4. Relationship of leucocytes count with congestive heart failure in different type of MI

\begin{tabular}{|c|c|c|c|c|c|}
\hline \multirow{2}{*}{ Type of MI } & \multirow{2}{*}{ TLC } & \multicolumn{2}{|c|}{ Heart Failure } & \multirow{2}{*}{ Total } & p value \\
\cline { 2 - 5 } & & Present & Absent & N(\%) & \\
\hline Anterior & $>11.0 \times 10^{9}$ & $\mathbf{n}(\%)$ & $14(34.1)$ & $44(57.1)$ & 0.001 \\
\hline & $\leq 11.0 \times 10^{9}$ & $6(16.7)$ & $27(65.9)$ & $33(42.9)$ & \\
\hline & Total & $36(46.8)$ & $41(53.2)$ & $77(100.0)$ & 0.004 \\
\hline Inferior & $>11.0 \times 10^{9}$ & $16(80.0)$ & $13(37.1)$ & $29(52.7)$ & \\
\hline & $\leq 11.0 \times 10^{9}$ & $4(20.0)$ & $22(62.9)$ & $26(47.3)$ & \\
\hline NSTEMI & Total & $20(36.4)$ & $35(63.6)$ & $55(100.0)$ & 0.131 \\
\hline & $>11.0 \times 10^{9}$ & $5(83.3)$ & $4(33.3)$ & $9(50.0)$ & $9(50.0)$ \\
\hline
\end{tabular}

Figure in parenthesis indicate percentage, $\mathrm{n}$ denotes number of patients.

$p$ value reached from chi- square test.

MI- myocardial infarction, NSTEMI- non ST elevation myocardial infarction,TLC - total leucocyte count,

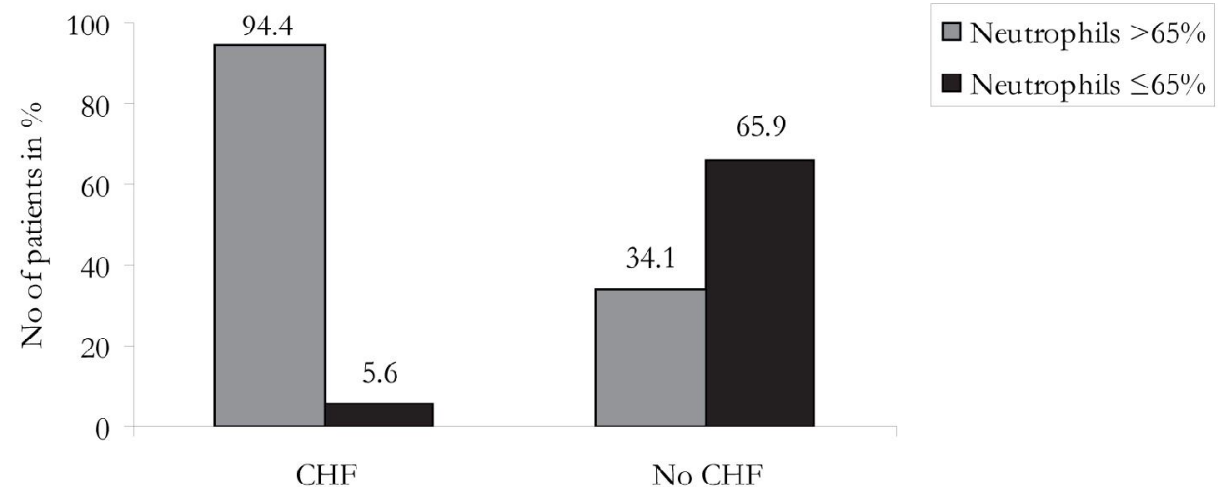

Fig. 1 Relationship of neutrophil count with heart failure in anterior MI

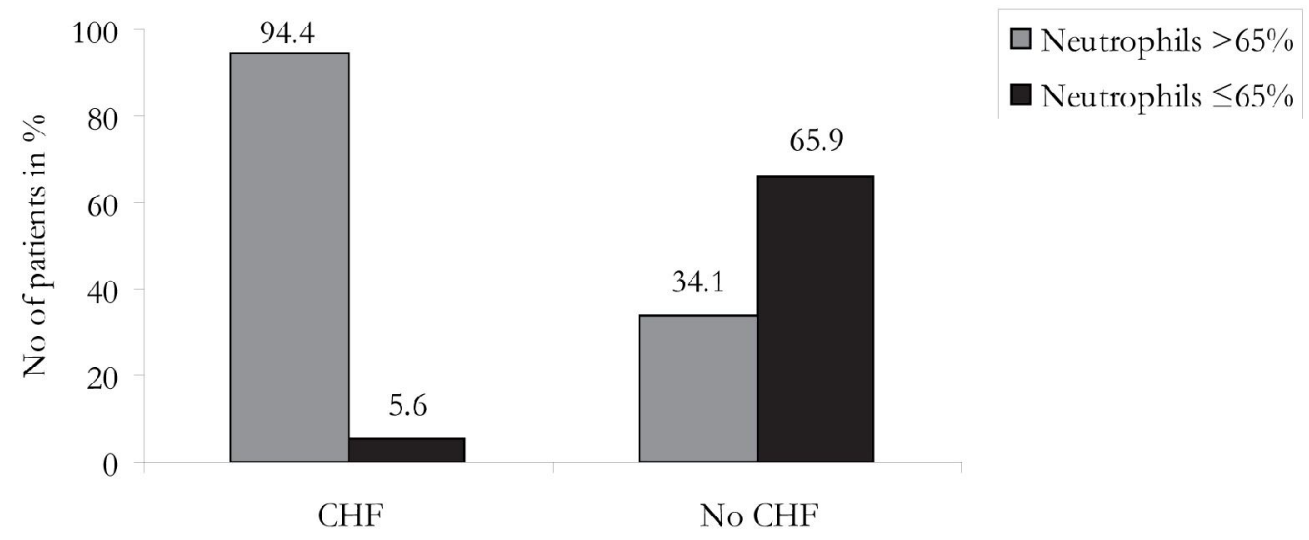

Fig.2. Relationship of neutrophil count with heart failure in inferior MI 


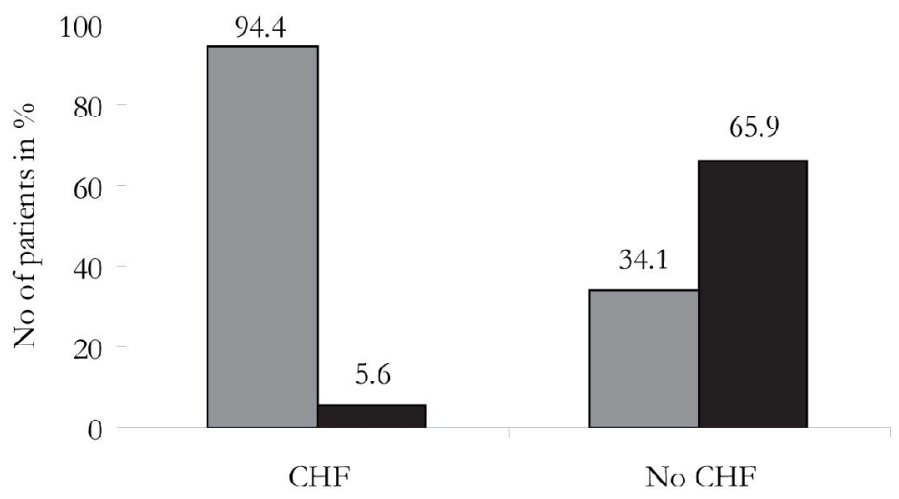

$\square$ Neutrophils $>65 \%$

Neutrophils $\leq 65 \%$

Fig.3. Relationship of neutrophil count with heart failure in NSTEMI

\section{Discussion}

The main objective of the study was to find out the association between neutrophilic leucocytosis on admission and early development of congestive heart failure in patients with acute myocardial infarction. Heart failure is related to extent of myocardial damage. Heart failure after acute myocardial infarction occurs when $25 \%$ of the ventricular muscle is compromised ${ }^{11}$. The result of this study suggested that the presence of neutrophilic leucocytosis and relative neutrophilia is strongly associated with early development of CHF in patients with AMI. Barron et al ${ }^{12}$ has earlier demonstrated the prognostic importance of the neutrophil count for coronary events and made a remark that patients with elevated WBC count have higher risk of developing an acute myocardial infarction as well as development of complications like congestive heart failure. And in another study carried out by Thompson et al in patients admitted to the hospital with chest pain, relative lymphocytopaenia and relative neutrophilia were found to be accurate early markers of AMI. ${ }^{13}$ This study demonstrated that the presence of neutrophilic leucocytosis measured at the time of hospital admission in patients with AMI may be a useful indicator to find out patients at risk of developing congestive heart failure independent of risk factors. This study is very much supported by the study of Furman et $\mathrm{al}^{10}$ who demonstrated a strong and consistent association between leucocyte count and all causes of mortality including congestive heart failure from $A M I$, independent of other therapeutic and prognostic factors. Furman et. al. ${ }^{8}$ in their multinational study also, demonstrated that, in patients with full spectrum of acute coronary syndrome, WBC count is independently associated with the development of congestive heart failure. Analysis also revealed that leucocyte count is positively correlated with neutrophil count, CHF, CK$M B$ and age but negatively correlated with lymphocyte count and mean ejection fraction (EF). This finding is however contrary to the finding suggested by Kyne et al. ${ }^{7}$ who stated that there was no association between the admission CPK activity level and leucocytosis, neutrophilia or CHF. But in the study carried out by Green et al. ${ }^{14}$ on 688 subjects of chest pain with nondiagnostic ECG found CK-MB level to be positively correlated with total WBC count following AMI. Present study is also supported by the study of J ones et al. ${ }^{15}$ who found WBC count $>10 \times 10^{9} / \mathrm{h}$ had elevated CK-MB level.

The physiological basis for the association between neutrophilia and the risk of coronary events after acute myocardial infarction has been studied in several animal models. ${ }^{16}$ Infiltration of neutrophils into ischaemic myocardium is an integral component of the post acute myocardial infarction inflammatory response. However, once activated neutrophils can change shape and adhere to the vascular endothelium, by increasing the vascular resistance and impairing dilatation of small coronary arterioles, they cause further myocardial ischaemia. ${ }^{17}$ Neutrophils thus mediates the vascular injury with subsequent ischaemia which compromises the activity of ventricular muscle.

Neutrophils also undergo cellular respiratory bursts and release $\mathrm{O}_{2}$ derived free radicals, which are toxic to cells. Interactions between infiltrating neutrophil and resident inflammatory cells within the myocardium may occur, resulting in the release of lysosomal enzymes and arachidonic acid metabolites, which may increase coronary artery resistance, leading to the development of myocardial dysfunction. ${ }^{18}$ Neutrophilia also occur in response to myocardial necrosis, which is a potent acute phase stimulus that is associated with local and systemic inflammatory response. Thus it is also a marker of the intensity of the peri-infarction myocardial inflammatory response. ${ }^{19}$

Neutrophilic leucocytosis may simply be a 
marker of congestive heart failure or a causative agent. In this study it is not possible to establish whether there is causal relationship between neutrophilia and congestive heart failure. As the mechanism responsible for this association is unknown several hypotheses have been postulated, including leucocyte mediated hypercoagulable state, leucocyte mediated no reflow, and indirect cytotoxicity mediated through proinflammatory cytokines. ${ }^{12}$

\section{Conclusion}

Commonest cause of morbidity and mortality after myocardial infarction is the development of congestive heart failure. This prospective observational study was aimed at finding out the relationship between neutrophilic leucocytosis and early development of heart failure after acute myocardial infarction. The study demonstrated a significant association between neutrophilic leucocytosis and even relative neutrophilia on admission to the hospital and the subsequent development of congestive heart failure in patients with ST elevation myocardial infarction with good sensitivity, specificity and predictive accuracy. The study suggests that neutrophilic leucocytosis may serve as a simple non invasive marker to identify the patients at higher risk for the development of congestive heart failure after acute myocardial infarction. Monitoring neutrophilic leucocytosis may serve as a key to anticipating one of the dreadful complications of acute myocardial infarction and triage of patients may be possible to prevent fatal consequences. The finding of this study can be very much helpful to identify the patients who may develop congestive heart failure and to take further decision at the periphery of the country where facilities for the investigation and management of patients are not adequate. Even at the centers with adequate intervention facilities, this simple investigation may help to be prepared for rescue procedures.

\section{Study limitations}

The present study dealt a relatively small number of cases. Selection bias may have occurred because sicker patients are often referred to this hospital. Cigarette smoking was not controlled in this study although previously it has been shown to be associated with leucocytosis and the risk of ischemic events. Other markers of inflammation like C-reactive protein were not measured. Another limitation of this study is that the neutrophil count was measured at only one point in time and this point was not consistent with all patients studied. Beside only short term inhospital complications were observed among the study subjects. As an observational investigation it can only identify association and not causality. Some drugs like $\mathrm{B}$-blocker and aspirin may have altered the trend of WBC count.

\section{References}

1. Vanderwal, A.C., Becker, A.E., Vanderloos, C.M., Das, P.K. 1994, 'S ite of initial rupture or erosion of thrombosed coronary atherosclerosic plaque is characterized by an inflammatory process irrespective of the dominant plaque morphology', Circulation, vol.89, pp. 36-44.

2. Falk, E.\& Fuster, V. 2001, 'Atherogenesis and its determinants', in Hurst's The Heart, eds. V. Fuster, R.W. Alexender \& R.A.O'Rourke, McGraw-Hill, New York, pp.1065- 1083.

3. Danesh, J., Collins, S., A ppleby, P., P eto, R. 1998, 'Association of fibrinogen, C- reactive protein, Albumin, and Leucocyte count with coronary heart disease; Meta-analysis of prospective studies', J AMA, vol. 279, pp.1477-1482.

4. Antman, E.M., Braunwald, E. 2001. 'Acute Myocardial Infarction', in Heart Disease, eds Braunwald E., Zipes D.P.\& Libby P.,W.B.Saunders Co. Philadelphia, pp. 11141231.

5. Emanuelsson, H., Karlson, B.W., Herlitz, J. 1994, 'Characteristics and prognosis of patients with acute myocardial infarction in relation to occurrence of congestive heart failure', E Heart J, vol.15, pp 761-768.

6. Dhalla, A.R., Hill, M.F., Singal, P. K. 1996, 'Role of oxidative stress in transition of hypertrophy to heart failure', J Am Coll of Cardiol, vol.28, pp 506-514.

7. Kyne, L., Hausdorff, J. M., Knight, E., Dukas,L., Azhar, G., Wei, J.Y. 2000, 'Neutrophilia and congestive heart failure after myocardial infarction', Am Heart J , vol. 139, pp. 94-100.

8. Furman, M.I., Anderson, F.A., Boudaz, A.,Goodman,S.G., Avezum, A., Sendon, L. A., Mukherjee, D., Dabbous, O.H, Goldberg R.J., Global, R.J.,GRACE, Investigators, 2004, 'Elevated leucocyte count and adverse hospital events in patients with acute coronary syndromes: findings from the Global Registry of Acute Coronary Events', Am Heart J, vol.147, pp.42-48. 
9. Menon, V., Lessard, D., Yarzebski, J ., furman, M., Gore, J .M., Goldberg, R.J . 2003, 'Leucocytosis and adverse Hospital Outcomes after Acute Myocardial Infarction', Am J Cardiol, vol.92, pp.368-372.

10. Furman,M.L.,Backer,R.C.,Yarzebski,J ,,Savfeg eau,J .,Gore,J.M.,Goldberg,R.J. 1996, 'Effect of Elevated Leucocyte count on In-Hospital Mortality Following Acute Myocardial Infarction', J ACC,vol.78,pp945-948.

11. Alexander,RW.,Patt C.M., Ryan T.J ., Roberts R 2001, 'Diagnosis and management of patients with myocardial infarction' in Hurst's The Hear,eds. V. Fuster, R.W. Alexander \& R.A O'R ourke, McGraw-Hill, Newyork, pp.12751360.

12. Barron, H.V., Cannon, C.P., Murphy, S.A., Braunwald, E., Gibson, C.M. 2000, 'Association between WBC count, epicardial blood flow, myocardial perfusion, and clinical outcomes in the setting of acute myocardial infarction', Circulation, vol.102, pp. 2329- 2334.

13. Thompson,S.P., Gibbons,R.J., Smars,P.A., Suman,V.J., $\quad$ Pierre,R.V., $\quad$ Santrach,P.J ., J iang,N.S. 1995, 'Incremental value of the leucocyte differential count and the diagnosis of myocardial infarction', Ann Intern Med., vol.122, pp.335-341.

14. Green, S.M., Vowels, J., Waterman, B., Rothrock, S.G., Kuniyoshi, G. 1996, Abstract of 'Leucocytosis: a new look at an old marker for acute myocardial infarction', Academic Emergency Medicine, vol.3, pp.1034 -1041.

15. Jones,S.P., Weisley,G.G., Palazzo,A.J., Granger,D.N., Grisham,M.B., Huang,P.L. Lefer,D.J. 1999, 'Myocardial reperfusion injury is exacerbated in the absence endothelial cells nitric oxide synthatase', Am J physiol Heart circ. Physiol, vol.276, pp.1557-1573.

16. Dreyer, W.J., Michael, L.H., West, M.S.,S mith, C.W., Rothlein, R., Rossen, R.D., Anderson, D.C., Entman, M.L. 1991, 'Neutrophil accumulation in ischaemic canine myocardium: insight into time course, distribution, and mechanism of localization during early reperfusion', Circulation, vol.84, pp 400-411.

17. Weiss S.J. 1989, 'Tissue destruction by neutrophil', N Engl J Med, vol. 320, pp.12411251.

18. Mikelson, J.K., Simpson, P.J., Lucchesi, B.R . 1988, 'Myocardial dysfunction induced by platelet activating factor in the post infracted rabbit isolated heart', J Mol Cell Cardiol, vol.20, pp 547-561.

19. Entman, M.L., Micheal, L., Rossen, R.D., Dreyer, W.J ., Anderson, D.C., Taylor, A., S mith, C.W. 1991, 'Inflammation in the course of early myocardial ischaemia', FASEB J, vol. 5, pp. 2529-37. 